\title{
A INTERDISCIPLINARIDADE ENTRE OS MUSEUS E A SALA DE AULA
}

\author{
Caroline Moreira do Amaral ${ }^{1}$ \\ Rodrigo Ademir da Silva ${ }^{2}$
}

\section{Resumo}

Tendo por base a importância dos museus na educação e cultura dos estudantes do Brasil e do mundo, principalmente do ensino fundamental - um dos maiores públicos visitantes dos museus brasileiros - faz-se necessário aprofundar o tema e analisar ações educativas que podem auxiliar no processo de ensino antes e após uma visita a um museu. Aborda-se neste artigo a importância dos museus e suas ações educativas no ensino escolar e a relevância de se fazer uma visitação com o melhor planejamento possível.

Palavras-chave: Ação Educativa. Ensino. Escola. Museus.

\section{INTRODUÇÃO}

Museus são espaços associados, na maioria das vezes, ao passado e também a fatos históricos. Guardam em sua memória objetos e documentos que contam um pouco de história, mas que também associam muito de seu significado ao presente. São lugares que testemunham o tempo e levam a reflexão social através de seus acervos. Atualmente os museus exercem um importante papel na educação, pois provocam um senso de aprendizagem que ultrapassa a complementaridade do ensino escolar, que ocorre através de métodos diferentes daqueles utilizados em sala de aula. Por conta da importância dos museus no aprendizado, é essencial estudar a relação que pode haver entre a escola e o universo museológico.

Em diversas situações as escolas levam seus alunos aos museus, com o objetivo de aprofundar vários temas vistos nas salas de aula. A preocupação do professor gira em torno de vários fatores na visita, principalmente ao conteúdo que pode ser estudado. Porém, além do fator aprendizado, o museu busca ensinar em um ambiente novo, diferente da sala de aula, proporcionando mais interesse e prazer ao aluno em aprender. Ir ao museu, neste caso, é um complemento do ensino escolar.

A ação educativa em museus busca ampliar o aproveitamento pedagógico dos acervos, para que os visitantes tenham um bom aproveitamento do conteúdo aprendido nos museus que muitas vezes é um gancho do assunto já visto em sala de aula ou pode ser uma introdução para o que vai ser aprendido. Para a maioria dos professores, levar os alunos para uma visita ao museu foge ao senso de organização, uma vez que alunos fora de classe se agitam e podem "esquecer" um pouco da disciplina exigida no dia-a-dia na sala de aula. Além disso, a

\footnotetext{
${ }^{1}$ Bacharel em Comunicação Social Publicidade e Propaganda e Estudante de Licenciatura em Letras Português e Inglês. Email: carolinemamaral@yahoo.com.br.

${ }^{2}$ Professor Orientador: Rodrigo Ademir da Silva - Graduado em Pedagogia pela UDESC (2006). Especialista em Metodologias Inovadoras em Educação com ênfase em Gestão, Orientação e Supervisão Escolar UNINTER (2007). E-mail: esp.rodrigo@ hotmail.com
} 
visitação com os alunos exige maior disposição e organização. O planejamento neste caso é de extrema importância, para antecipar problemas e distrações que podem vir a ocorrer. Segundo LIBÂNEO, 1994:

O planejamento escolar é uma tarefa docente que inclui tanto a previsão das atividades em termos de organização e coordenação em face dos objetivos propostos, quanto a sua revisão e adequação no decorrer do processo de ensino. O planejamento é um meio para programar as ações docentes, mas é também um momento de pesquisa e reflexão intimamente ligado à avaliação.

É importante destacar que o a visita ao museu deve ser um trabalho conjunto entre o professor, os alunos e os profissionais que trabalham com ação educativa nestas instituições. Este artigo será voltado principalmente para professores, pois várias vezes estes precisam de mais preparo antes de uma visitação com os estudantes. É relevante a realização de estudos relacionados às ações educativas que podem ser exploradas pelas escolas nas visitas aos museus.

\section{A RELAÇÃO MUSEU-ESCOLA}

Museus são instituições que já existem há séculos e que trazem em seus objetos fragmentos da história, fazendo uma reflexão social através dos seus documentos e acervos. Segundo a definição do ICOM (Conselho Institucional de Museus, 2001) museu é uma "instituição permanente, sem fins lucrativos, a serviço da sociedade e do seu desenvolvimento, aberta ao público e que adquire, conserva, investiga, difunde e expõe os testemunhos materiais do homem e de seu entorno, para educação e deleite da sociedade". Já por Francisco Ramos (2004), podemos entender o museu como um local onde pode-se examinar bens culturais e apreender as informações que deles emanam, vivenciando uma prática diferente das rotinas diárias. São também espaços que favorecem o aprendizado, unindo educação com lazer, transmitindo sensibilidade e sentimentos variados.

O conceito de museu teve seu princípio na vontade do homem de reunir objetos, colecionar e expor pertences diversos. Desde a antiguidade os indivíduos desenvolveram rotinas para juntar objetos e estudar os conhecimentos que eles possuem. A palavra "museu" que tem sua origem na Grécia antiga e significa "templo das musas" e já era utilizada para denominar o local onde, na Alexandria, eram realizados os estudos das artes e das ciências. Atualmente os museus são instituições designadas para transmitir conhecimento aos visitantes no passo que estes se conectam com os itens em exposição. Na realidade, segundo Silva, os museus sempre tiveram a intenção de educar através de suas exposições, seja transmitindo informações ou no intuito de formar identidades, perspectiva de educação argumentada por educadores críticos e pós-críticos. Para Pacheco (2012):

Do ponto de vista pedagógico o museu é o local onde se realiza tanto a pesquisa sistemática sobre o assunto que ele expõe como o espaço de sensibilização do público para determinados temas e assuntos. Do ponto de vista didático o museu serve tanto ao ensino dos conteúdos factuais, possibilitando a coleta e sistematização de informações pontuais, como aponta para o desenvolvimento das habilidades e da sensibilidade de cada visitante.

O entendimento geral estabelece, equivocadamente, que o acervo do museu é composto de velharias e itens do passado e este conceito acaba sendo utilizado para os museus de modo abrangente. Esquece-se que existem diferentes acervos nos museus e que estes se renovam utilizando novos estilos, sistemas, tecnologia e ferramentas que tornam estas 
instituições mais dinâmicas e interessantes. Os museus também se singularizam quanto à sua estrutura e organização. Exemplos disso são museus de cidades pequenas que geralmente são compostos de itens diversos, expostos mais pela intenção de colecionar objetos do que por um sentido exato e valor histórico do acervo, Pacheco (2012). Os museus mais atuais trazem a tecnologia para suas exposições, atraindo a atenção do visitante para além dos objetos e documentos exibidos. Todos podem ser aproveitados pelos professores para educar por meio da conexão com o acervo.

O museu é um ambiente educativo peculiar. Ele tem um acervo de registros selecionados da vivência sócio-histórica. Ele tem, afinal, materialidade e oportunidades de simbolização não encontradas na escola. E é a partir de uma educação para olhar através dessa materialidade (dispersa, contraditória, lacunar e plural) que se realiza seu papel educador, sua peculiaridade e sua potencialidade. (SIMAM, et al, 2007, p. 37)

Estudar de maneira didática os museus e acervos é de extrema importância para o melhor aproveitamento escolar e já existem projetos e sugestões para isso, dentre elas a Metodologia da Educação Patrimonial, propagada por Maria de Lourdes Horta, e a Metodologia Triangular, manifestada por Ana Mae Barbosa. Em síntese, pode-se dizer que a Educação Patrimonial educa através do objeto cultural exposto e é ainda conhecida no Brasil como Ação Educativa. Sugere uma metodologia composta de quatro etapas, sendo elas observação, registro, exploração e apropriação. (HORTA, 1999). Esta abordagem é estudo fundamental para refletir sobre as ações educativas focadas nos bens culturais explanadas no museu ou fora deste.

A metodologia específica da educação patrimonial pode ser aplicada a qualquer evidência material ou manifestação da cultura, seja um objeto ou um conjunto de bens, um monumento ou um sítio histórico ou arqueológico, uma paisagem natural, um parque ou uma área de proteção ambiental, um centro histórico urbano ou uma comunidade da área rural (HORTA, 1999, p. $6)$.

Já a metodologia triangular tem seu primórdio nos museus de arte, está voltada no progresso da percepção e desfrute do objeto e busca inserir a obra na história da arte, no contexto histórico de criação do autor. Resumidamente falando, esta metodologia sugere três abordagens para se construir conhecimento de arte, que são elas a interpretação da obra pelo público, sua contextualização histórica e o estudo sobre o momento histórico da produção da obra. Portanto a utilização do museu na rotina escolar deve vincular os assuntos abordados na exposição visitada e ainda, promover uma programação ao retorno à sala de aula após a visita, aproveitando a bagagem cultural adquirida para a execução de um projeto educativo. Para atingir seu perfil educativo, o museu define-se então, como o lugar onde os objetos são exibidos para construir um argumento crítico. É preciso criar um planejamento para sensibilizar o público para um maior engajamento com o museu. Busca-se um estímulo para melhorar a educação indireta, vinculada a uma percepção mais crítica sobre a sociedade em que vivemos e que viver de modo mais expansivo.

Nos últimos anos, cada vez mais pesquisas vêm sendo realizadas com o intuito de enfatizar o museu como espaço educacional. O papel educacional adquirido pelos museus vem do fato de que o público escolar tem marcado bastante presença nestes espaços culturais e cada vez mais professores se interessam por conhecer melhor os museus, tendo por objetivo garantir um melhor aproveitamento dos mesmos pelos alunos. As visitas mediadas, muitas vezes significam o deslocamento para os museus da rotina de ensino das salas de aula. Segundo Lopes (1991), "chamamos escolarização a esse processo de incorporação pelos 
museus das finalidades e métodos do ensino escolar [...] e vêm se aprofundando no bojo das propostas de educação permanente para os museus".

A relação entre museu e escola pode ser enfocada a partir de dois pontos de referência, sendo um o museu e o outro a própria escola. $\mathrm{O}$ processo de ensino na escola possui rotinas para um melhor ensinamento e os educadores e alunos devem adquirir estas para que haja êxito no aprendizado. De acordo com Trigueiros (1958, p. 16)

A integração do trabalho educacional dos museus com o programa dos institutos pode dar prestígio, elevar o nível e melhorar os métodos de ensino. Os mestres de todos os graus de ensino devem ter conhecimento adequado dos recursos e utilidades dos museus. Assim, instamos que todos os programas de preparação para o magistério incluam oportunidades de treinamento no uso dos museus de sua técnica.

Os museus vêm sendo vistos como espaços que possuem uma forma própria de desenvolver suas ações educativas e acabam sendo identificados como estabelecimentos de educação não-formal. $\mathrm{O}$ aprendizado do aluno pode ocorrer em diversos campos educativos e não só no ambiente escolar. A educação em museus é um campo de estudos bastante abrangente, uma vez que museus são instituições que possuem um acervo rico quanto à sua história, público freqüentador diversificado e contexto sócio-cultural. Porém, a proposta educativa dos museus é diferente da proposta educativa escolar: "nos museus a base está na observação dos objetos assumindo como primordial a linguagem visual ao invés da verbal" (SILVA, p. 6).

Para empregar o museu como um suplemento escolar é necessário pensar que a visita começa muito antes dos professores e alunos irem ao museu, assim como se prolonga após a visita. Um excelente planejamento da atividade é o que vai influenciar se a visita será de qualidade e se haverá um bom aproveitamento pedagógico. A antecipação das ações conduz o desempenho dos alunos para as atividades didáticas e permite aumentar o resultado educativo da experiência para os estudantes.

É comum as visitas escolares serem vistas como visita de lazer para os alunos e, ainda, há momentos em que o professor deixa os alunos fazerem o que quiserem dentro do museu e aproveitam aquele momento para uma folga das aulas. Muitos chamam estas visitas de "passeio escolar" e são momentos em que tanto educadores como os alunos esperam que não haja nenhum compromisso com o aprendizado. Realizar um planejamento de excelência começa com a visita do professor ao museu em data prévia a visita dos alunos. É essencial que o professor consiga visualizar as oportunidades didáticas e imaginar as atividades que poderão ser desenvolvidas em cima da visita. Não menos importante é a pesquisa sobre o acervo exposto antes da visita, bem como um diálogo com o setor educativo da instituição, para trocar idéias de principais ações que podem ocorrer durante e após a ida ao museu. Muitos museus possuem este setor, que sugerem atividades lúdicas para fixar o assunto visto durante a visitação e também auxiliam em como abordar o assunto que será visto no acervo durante as aulas na escola.

Alguns museus possuem um espaço amplo para as exposições, sendo elas de acervo permanente ou rotativo. Mesmo que haja livre acesso para todas as áreas abertas ao público, pode-se optar por quais conteúdos serão utilizados nas atividades escolares pelos alunos. É reservado ao professor planejar o tema da visita, delimitar as informações que serão mais interessantes estudar com base no que está sendo visto na sala de aula e deliberar sobre as atividades que serão requisitadas aos alunos. É aconselhável no momento do agendamento 
entrar em contato com o setor educativo do museu para saber se o museu possui mediadores para conduzir para a turma, se estes conseguem introduzir os temas vistos na sala de aula no percurso a ser visitado, se o museu inclui na visita alguma atividade educativa para aplicar após o percurso, entre outras questões que podem surgir durante o planejamento e acabam atrapalhando as atividades se não forem esclarecidas com antecedência. Segundo Pacheco (2012), é necessário um planejamento didático que preveja três momentos:

A inserção do tema da exposição a ser visitada no programa da disciplina e a construção de um instrumento de registro da visita; a visita em si para a coleta de informações sobre o tema estudado; o uso das informações do museu em sala de aula para aprofundamento do tema estudado e a confecção de um produto final. Estes momentos devem estar ligados por uma atividade a ser desenvolvida sucessivamente nos diferentes momentos e espaços. Ou seja, é preciso trazer o museu para a sala de aula, levar os assuntos de aula para o museu e retornar a sala com as informações e impressões da visita.

Antes de sair para visita, na escola, é preciso estimular os alunos questionando e discutindo sobre quais informações podem ser adquiridas na visita. Planejar a ida ao museu ajuda a definir os conteúdos que serão explorados no museu. É recomendado utilizar livros, materiais de divulgação da exposição, como folders e cartazes, visitar o site do museu para visualizar detalhes do acervo, etc. No planejamento com os alunos também deve ficar claro qual será a forma de registro que será feito durante a visitação. "O instrumento mais utilizado para isso é o relatório: texto extenso onde se descreve a maior quantidade de informações coletadas na visita, sem a necessidade de articular estes dados entre si ou com as informações das aulas anteriores" (PACHECO, 2012). É importante também planejar com os alunos o que será feito na escola após a visita, levando em conta o que foi pedido como registro. Por exemplo, se foi pedido relatório, este será o resultado final, ou seja, a entrega deste para o professor. Se forem solicitadas fichas de registro, estas podem ser transformadas em catálogos da exposição. Para alunos menores, pode-se ainda solicitar algum trabalho artístico de algum tema relacionado à exposição. Se forem permitidas fotografias durante a visita, podem ser feitas impressões destas. As fotos podem ser utilizadas para produção de narrativas sobre a visita ou trocadas entre a turma. Também podem ser feitos painéis que apontem momentos variados da visita ou pedir para que cada aluno mostre para a sala a foto de um item do acervo e explane sobre as informações deste e o que o objeto representa.

Se o professor produzir com a turma fichas de observação, também podem aproveitar as informações para discutir estas informações, utilizando o material escolar. Numa aula de história, por exemplo, os dados históricos estudados no museu serão confrontados com os dados históricos dos materiais didáticos. Para variar esta ação, grupos podem ser formados para planejarem apresentações sobre os temas vistos na visitação.

No museu, ao chegar, vários professores ficam longe dos alunos com a intenção de deixar os monitores responsáveis pela ordem e disciplina dentro da instituição, porém isto não é aconselhável, pois dificulta o trabalho dos mediadores e a turma percebendo que o professor não está prestando muita atenção à visita acaba também perdendo o foco, achando que não é importante aquela atividade. Com isso, é necessário que o professor esteja sempre junto aos alunos, podendo até ajudar o mediador com complementos nas explicações e fazendo pontes entre as aulas, os alunos e o museu. Comentários realizados durante a mediação, tanto pelos professores quanto pelos alunos, são sempre bem vindos, pois demonstram que a turma está preparada e motivada para a atividade e induz os estudantes a prestarem cada vez mais atenção, ou seja, faz da visita, realmente, um momento de estudo. Segundo Bittencourt (2004, p. 358) "O princípio básico do método de investigação de objetos reside na observação livre e na observação dirigida. Com a observação pretende-se que o aluno aprenda a 'ver', seja capaz 
de parar diante de um objeto, fixar e concentrar o olhar sobre ele." O objetivo deste momento é utilizar no ambiente escolar uma linguagem própria dos museus como auxílio para a relação do que foi vivenciado e aprendido durante a visitação. Assim não apenas se encerra uma atividade diferente e prazerosa como desperta nos estudantes o interesse para futuras visitas aos museus, não só como atividade escolar, mas como momento de lazer fora do ambiente escolar.

\subsection{AÇÃO EDUCATIVA NOS MUSEUS}

A ação educativa nos museus começou a ganhar espaço no fim do século XIX. Na Europa, neste período, criaram-se os primeiros departamentos de educação nos museus, onde a educação era abordada para dar acesso a todas as formas de conhecimento para a população. No Brasil a ação educativa teve avanços a partir de 1920, influenciada pela proposta pedagógica de Fernando de Azevedo, que determinava a modernização dos museus conferindo-lhe papel de complemento do ensino escolar. Na década de 1960, ações propagadas pela UNESCO visaram aos museus ações complementares para educação do Ensino Fundamental. A idéia de museu ser um complemento para a educação permanece até hoje. A educação educativa em museus busca aumentar o aproveitamento pedagógico nos acervos, para que o visitante amplie seu lado crítico em relação à sua realidade e sua história.

Toda a ação educativa precisa passar por um planejamento. $\mathrm{O}$ museu ainda é visto por muitos educadores como um complemento da sala de aula, ou seja, o assunto principal é ensinado na sala de aula e a visita ao museu só é utilizada como finalização e passatempo. Outra ilusão ainda vista pelos professores é de que somente o mediador do museu pode servir como educador naquele espaço, cabendo ao professor somente o papel de organizar o passeio e acompanhar os alunos.

Segundo Fortuna (2006, p.10)

Um dos problemas que os professores enfrentam quando levam seus alunos ao museu, ou quando pretendem explorar uma visita ao museu na sala de aula, relaciona-se ao como fazer os alunos verem o que olham. Em uma visita ao museu, tudo já sugere um clima de jogo: o simples fato de sair do espaço e do tempo regular da aula, as novas interações oportunizadas (com os colegas, professores, pessoal do museu), os desafios que a novidade coloca, a aura de mistério e de magia do encontro com sua própria história e com o novo, ou o velho revisitado, e a associação à idéia de lazer e passeio.

Estar perto dos objetos, imagens e documentos escritos dos museus é muito diferente de um ensinamento verbal da sala de aula. Para o aluno é uma experiência singular e insubstituível. Espera-se que o professor estimule o aluno a estudar e analisar mais profundamente o que está em exposição. Mesmo que alguns museus já possuam materiais educativos que auxiliarão na aprendizagem dos assuntos abordados na visita, para disponibilizar para a escola e professores, muitos ainda não têm tal instrumento de apoio, por isso é muito importante que seja elaborada essa ferramenta que complementará a visita.

Para Martins, "as ações educativas são estratégias que permitem ao visitante entrar em contato com a perspectiva daqueles que conceberam a exposição; mas também permitem construir seus próprios significados sobre aquilo que se vê". Os educadores, por meio de suas ações, entram em contato com os vários públicos que visitam os museus, auxiliando na compreensão e interpretação do acervo. Os setores educativos que estão ativos nos museus desde o fim do século XIX, foram implantados para dialogar com o público sobre os significados que os responsáveis pelas exposições gostariam de transmitir. 
Muitas são as ações utilizadas pelos educadores para dialogar com os públicos nos museus. Os objetivos dessas atividades variam de acordo com o tipo de museu e a formação da equipe. Ainda segundo Martins (2013, p.34):

No Museu de Arqueologia da Universidade de São Paulo (MAE-USP), um museu de ciências humanas, o objetivo geral das atividades educativas é promover a discussão sobre a diversidade cultural. Os educadores desse museu consideram importante incentivar a discussão desse tema para aumentar a tolerância e a compreensão entre os diferentes grupos humanos. Para isso, são feitas atividades para explorar os objetos das coleções de arqueologia e etnologia brasileiras, européias e africanas de seu acervo. Essa exploração pode ser feita pela observação, pelo tato, pela resposta a perguntas dos educadores, pela confecção de desenhos e outras ações centradas na compreensão dos objetos expositivos.

Com a intenção de atingir os diversos tipos de visitantes, investindo na qualidade da informação, os museus vêm investindo muito na formação de mediadores capazes de explanar não só sobre conteúdos específicos da instituição como também a forma como são repassados ao público, ou seja, boa comunicação visual, descontração e abertura para debates. O resultado que se deseja alcançar ao final da mediação não gira em torno da quantidade de informação repassada aos visitantes e sim na qualidade do que se deseja informar e das interações estabelecidas.

As interatividades, segundo Lubinski, que são possíveis de ocorrer durante as visitas variam muito, como hands-on, que considera a manipulação física como principal forma de interação; minds-on, quando há envolvimento intelectual e as idéias e pensamentos podem ser moldados durante ou após a visita, resultando em dúvidas e questionamentos; e, hearts-on, quando há emoção envolvida, já que a idéia da mediação e do próprio museu, muitas vezes, é de atingir a sensibilidade do visitante. As exposições podem privilegiar apenas um desses sentidos, porém é aconselhável ter a presença das três perspectivas, mesmo que realizadas em níveis variados.

Grinder e McCoy (1998) apud Marandino et. al. (2008) citam que de maneira geral, existem três tipos de visitação possível:

A visita-palestra, a discussão dirigida e a visita-descoberta. Na primeira delas, a visita-palestra, ocorre o aprofundamento de um tema da exposição por um especialista ou educador. Esse tipo de visita tem baixo nível interacional, atraindo o público adulto especificamente interessado no tema abordado. Na discussão dirigida, a mediação se faz por meio de questionamentos, de forma a proporcionar o entendimento de aspectos comunicacionais pertinentes àquela exposição. Para elaborar esses questionamentos e fomentar o debate, o educador estrutura um roteiro lógico, cujos objetivos educacionais foram previamente definidos e que deve ser adaptado para cada grupo recebido. O nível de interação é bastante alto nesse tipo de mediação, já que, para funcionar, pressupõe-se intensa participação do público. Na visita-descoberta, atividades ou jogos são propostos dentro do espaço expositivo. Ela possibilita a descoberta de novos elementos e olhares para um determinado conteúdo exposto. É o tipo de visita mais interativa, pois depende quase que exclusivamente do visitante para ser realizada. 
É vantajoso que as modalidades de visitação sejam utilizadas associadas umas às outras, atingindo vários níveis de interação. O melhor é prezar o relacionamento que promova o debate e comunicação dos visitantes. É de extrema importância o diálogo entre os estudantes, mediador e professor, para que haja um melhor aproveitamento das informações e conceitos adquiridos na visitação.

O Museu do Ceará (Fortaleza-CE), por exemplo, possui atividades que são oferecidas aos estudantes logo após a visitação, como oficinas de desenho ou jogos relativos à própria exposição. Se não existirem este tipo de atividades, o próprio professor pode sugerir uma brincadeira ou dinâmica que possa ser realizada pelos alunos em algum espaço disponibilizado pelo museu, utilizando somente papel e lápis de cor, como um desenho que conte um pouco do que foi visto na exposição, ou uma produção de texto com a síntese do relatório solicitado (PACHECO). O Museu Nacional do Mar (São Francisco do Sul-SC) possui um jardim amplo com cadeiras e bancos e que fica de frente para a Baía da Babitonga e para o Porto da cidade, um excelente espaço para que seja feita uma peça teatral rápida e improvisada em que grupos de alunos representem a história da navegação, por exemplo, tema da primeira sala de visitação do Museu.

\section{CONSIDERAÇÕES FINAIS}

Este artigo permitiu uma ampliação do conhecimento sobre as práticas pedagógicas Um bom planejamento é ferramenta de ponderação sobre as práticas pedagógicas que serão realizadas nas visitas aos museus. Ao escrever os objetivos, os conteúdos que deverão ser focados e os procedimentos que serão realizados, concretiza-se através da escrita a compreensão sobre o significado dos procedimentos pedagógicos. Paulo Freire já ensinava que "a rigorosidade metódica, onde o educador deve afirmar a rigorosidade do método com o qual trabalha, tendo clareza em seus objetivos e com um discurso que não pode ser diferente da prática", tendia a criar métodos e uma postura consciente, uma ação planejada para que haja leitura do objeto do museu, uma interpretação e estudo das informações do acervo e não uma memorização sem a intenção de um aprendizado rico e diferente para o aluno.

A intenção deste artigo é argumentar que a atividade didática junto ao museu não se atenha somente à hora da visitação, e sim que o museu seja utilizado dentro das salas de aula, e ainda utilizado como apoio didático para o ensino nas escolas. Os museus sempre foram ligados como um ambiente de aprendizagem, sendo esta exercida através dos objetos, dos vários sentidos. Uma aprendizagem vinculada ao objeto cultural, das relações críticos-sociais e das diversas formas de interpretação dos acervos. Para tanto, faz-se necessário que as visitas se iniciem ainda na sala de aula e se encerrem nela, ou seja, não fique só a parte da visita ao museu, mas que seja dada uma continuidade ao aprendizado adquirido lá, para as informações sejam confrontadas com os demais recursos didáticos utilizados na escola. Museu e sala de aula devem se complementar, caminhando juntos para uma educação mais completa. A ação educativa nos museus deve promover a sensibilização dos estudantes sobre a função dos museus como um espaço de memória nas sociedades contemporâneas. As atividades de ensino devem mobilizar os alunos para as necessidades de aprendizagem disciplinar e possibilitar o enriquecimento cultural dos estudantes.

\section{REFERÊNCIAS}

ALMEIDA, A. M. Desafios da Relação Museu-Escola. Comunicação e Educação, São Paulo, v. 10, p. 50-56, set/dez. 1997. 
ALMEIDA, A. M.; VASCONCELOS, C. M. Por que visitar museus. In: BARBOSA, A. M. Arte-educação pós-colonialista no Brasil: aprendizagem triangular. Comunicação e Educação, São Paulo, 21: 59 a 64, jan./abr. 1995. p. 63.

BITTENCOURT, C. O saber histórico na sala de aula. 11 ${ }^{a}$ Ed. São Paulo: Contexto, 2008. pp. 104-116.

FORTUNA, T.R. O Museu em Jogo. Revista Museu: 2006. Disponível em: http:// http://www.ufrgs.br/difusaocultural/admin/artigos/arquivos/artigotaniafortuna.pdf. Acessado em 15 jan. 2016.

FREIRE, P. Pedagogia da Autonomia. São Paulo, 2010, Ed. Paz e Terra.

GRINDER, A. L.; MCCOY, E. S. The good guide. A soucerbook for interpreters, docents and tour guides. Scottsdale: Ironwood Publishing, 1998 apud MARANDINO, M.; BIZERRA, A. F.; NAVAS, A. M.; FARES, Djana Contier; MONACO, L. M.; MARTINS, L. C.; GARCIA, V. A. R.; SOUZA, M. P. C de. Educação em museus: a mediação em foco. 1. ed. São Paulo: GEENF/FEUSP, 2008. V. 1.36 p. $\quad$ PDF disponível em www.geenf.fe.usp.br/publica.php

HORTA, M. L. P.; GRUMBERG, E.; MONTEIRO, A. Q. Guia Básico de Educação Patrimonial. Brasília: Instituto do Patrimônio Histórico e Artístico Nacional, Museu Imperial, 1999.

LIBÂNEO, J. C. Didática. 28. ed. São Paulo: Cortez Editora, 1990.

LOPES, M. M. A Favor da Desescolarização dos Museus. Campinas, 1991.

LUBINSKI, J. W. A favor del conocimiento científico (Los nuevos museos) Revista Valenciana D'Estudis Autonômics, n. 23, Segundo Trimestre, 1998, p. 295

MARANDINO, M.; BIZERRA, A. F.; NAVAS, A. M.; FARES, Djana Contier; MONACO, L. M.; MARTINS, L. C.; GARCIA, V. A. R.; SOUZA, M. P. C de. Educação em museus: $a$ mediação em foco. 1. ed. São Paulo: GEENF/FEUSP, 2008. V. 1. 36 p. PDF disponível em www.geenf.fe.usp.br/publica.php

MARTINS, L. C. Que Público é Esse? Formação de públicos de museus e centros culturais 1 ed. - São Paulo: Percebe, 2013.

PACHECO, R. A. O Museu na Sala de Aula: propostas para o planejamento de visitas aos museus. Revista Tempo e Argumento. Florianópolis, v. 4, n. 2, pp. 63-81, 2012.

SILVA, P. F. O Museu como Espaço Educacional: Um Olhar sobre o Instituto Ricardo Brennand. Artigo de Conclusão do curso de Pedagogia da UFPE. S.d.

SIMAN, L. M. C.; COSTA, C. M.; NASCIMENTO, S. S. do. Escola e Museus: diálogos e práticas. Belo Horizonte: Secretaria de Estado da Cultura/ Superintendência de Museus; Pontifícia Universidade Católica de Minas Gerais/ Cefor, 2007.

TRIGUEIROS, F. S. O Museu: Órgão de Documentação. Rio de Janeiro, 1958. 